\title{
Comparison of Three Different Paraspinous Unilateral Approaches to the Spinal Canal for Lumbar Decompression-Minimally 2-Year Postoperative Evaluation
}

\author{
Masahiro Morita $^{1^{*}}$ and Hiroaki Nakamura ${ }^{2}$ \\ ${ }^{1}$ Department of Orthopaedic Surgery, Izumi Municipal Hospital, Japan \\ ${ }^{2}$ Department of Orthopaedic Surgery, Osaka City University Graduate School of Medicine, Japan
}

"Corresponding author: Masahiro Morita, Department of Orthopaedic Surgery, Izumi Municipal Hospital, Japan, Tel: +81-725-41-1331; Fax: +81-725-43-3350; E-mail: m1908130@msic.med.osaka-cu.ac.jp

Rec Date: July 26, 2017; Acc Date: Aug 01, 2017; Pub Date: Aug 06, 2017

Copyright: (C) 2017 Morita M, et al. This is an open-access article distributed under the terms of the Creative Commons Attribution License, which permits unrestricted use, distribution, and reproduction in any medium, provided the original author and source are credited.

\begin{abstract}
Background: The purpose of this study is to investigate the differences of the clinical results and imaging findings among three different bilateral decompression via unilateral approach with a minimum 2-year follow-up period.

Methods: Thirty consecutive patients with lumbar spinal canal stenosis who had undergone bilateral decompression via 3 different unilateral paraspinous approaches with a minimum 2-year follow-up period were chosen retrospectively for groups A (conventional open surgery), B (mini open surgery), and C (micro-endoscopic surgery). The clinical results and imaging findings of these three groups were then investigated.
\end{abstract}

Results: A significant difference in length of incision and intraoperative blood loss per level decompressed was seen with group $A>B>C$. Operative time per level decompressed was longer in group $C$ than in groups $A$ or $B$. Japanese Orthopaedic Association (JOA) score recovery rate was lower in group $B$ than in group $C$. The change ratios of cross-sectional area (CSA) of the ipsilateral and contralateral multifidus were smaller in group $A$ than in groups $B$ or $C$. Ipsilateral facet joint preservation was less in group $A$ than group $C$, and contralateral facet joint preservation was less in group $A$ than in groups $B$ or $C$. The difference in change in slippage was greater in group $A$ than in group $\mathrm{C}$.

Conclusion: This study revealed that bilateral decompression via a unilateral approach using mini open or microendoscopic procedures could be better surgical interventions compared to a conventional unilateral open approach for paravertebral muscle and facet joint preservation for at least 2 years.

Keywords: Lumbar spinal canal stenosis; Decompression surgery; Less invasive surgery; Microendoscopic surgery

\section{Introduction}

Lumbar decompression using a posterior approach is a commonly performed surgical intervention for Lumbar Spinal Canal Stenosis (LSCS), and there are various posterior approaches to reach the spinal canal. Less invasive spinal procedures have come into wide use, and previous studies have found that less invasive surgeries have equal or superior outcomes compared to conventional open surgery [1-8]. The purpose of this retrospective case-control study was to determine whether the differences among 3 paraspinous unilateral approaches for lumbar decompression would suggest that less invasive procedures would have superior outcomes compared to conventional procedures for at least 2 years. There are no studies comparing differences in clinical results and imaging findings among 3 different unilateral approaches to bilateral decompression that we examined.

\section{Materials and Methods}

In the present study, we investigated differences in clinical results and imaging findings among 3 procedures. Thirty consecutive patients with LSCS who had undergone bilateral decompression via 3 different unilateral paraspinous approaches with a minimum 2-year follow-up period were chosen retrospectively for groups A (conventional open surgery), B (mini open surgery), and C (micro-endoscopic surgery). Decompression surgeries were performed before 2008 (group A), after 2008 (group B), and after 2011 (group C) by the first author. After 2011, micro-endoscopic surgery was indicated for within 2 levels decompression and mini open surgery for 3 or more levels decompression. To set the operation period among three groups close, every thirty patients were selected around 2007 in group A, 2008 in Group B, and 2011 in group C. Patients with a change in surgical site slippage more than $3 \mathrm{~mm}$ on preoperative lateral decubitus flexionextension X-rays were excluded. Approach side was decided with consideration of the patient's anatomy and symptoms. All patients presented with cauda equine symptoms with or without radicular symptoms who did not respond to conservative treatments, and they were observed postoperatively for at least 2 years. All patients underwent upright X-rays with anteroposterior and lateral views of the whole spine, lateral decubitus flexion-extension views of the lumbar spine, magnetic resonance imaging (MRI) of the lumbar spine at $1.5 \mathrm{~T}$, and computed tomography (CT) of the lumbar spine according to the 
Citation: Morita M, Nakamura H (2017) Comparison of Three Different Paraspinous Unilateral Approaches to the Spinal Canal for Lumbar

following schedule: before surgery (X-ray, MRI, and CT), 1 week after surgery (CT), and at final follow-up (X-ray and MRI).

Group A (16 men, 14 women) consisted of patients who had undergone loupe and a chisel decompression with cutting of the basal portion of the spinous process (e.g., for decompression of L3/L4/L5, the basal part of the spinous processes of L3, L4, and L5 were cut by chisel). The spinous processes with preserved ligamentous structures were not attached to their origins on closure. Group B (16 men, 14 women) consisted of patients who had undergone decompression using the same tools as those used in group A plus a retractor for mini open surgery, Quadrant (Medtronic Sofamor Danek, Tennessee, USA), without cutting the basal part of the spinous process. Group C (18 men, 12 women) consisted of patients who had undergone microendoscopic decompression using a high-speed drill without cutting of the basal part of the spinous process (Figure 1).
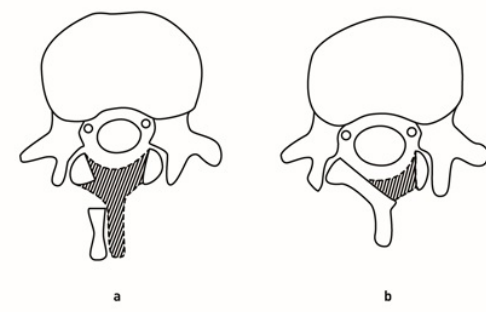

b

Figure 1: (a) In group A, the basal part of the spinous process is cut by a chisel, and the spinous process is retracted contralaterally to expose the interlaminar space. The caudal portion of the cranial lamina, cranial portion of the caudal lamina, medial portion of bilateral facet joints, and hypertrophied yellow ligaments are removed for decompression. (b) In groups B and C, the caudal portion of the cranial lamina and the cranial portion of the caudal lamina are removed by a chisel (group B) or a high-speed drill (group C) without cutting the basal part of the spinous process. Undercutting the contralateral laminae and removing the medial portion of the bilateral facet joints with hypertrophied yellow ligaments are performed for decompression.
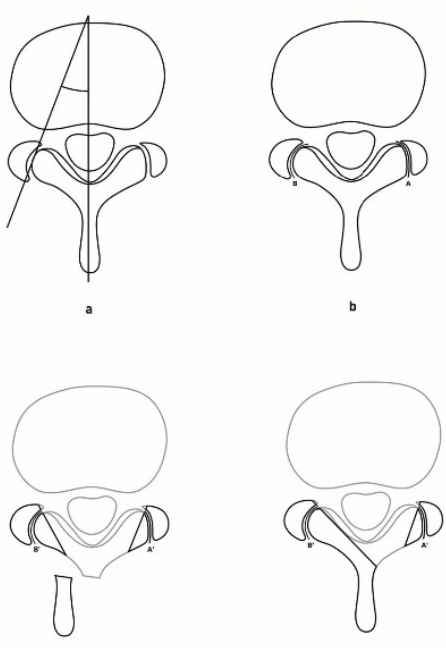

Figure 2: (a) Preoperative facet joint sagittalization using the axial computed tomography (CT) obtained just above the pedicle (e.g., for evaluation of the L4/L5 facet, the axial CT obtained just above the L5 pedicle was used) is defined as the angle between 2 lines, 1 made between each edge of the facet joint, and the other made by visual observation of the midpoint of the vertebral body and spinal canal. The numerical value of the angle would be smaller according to the severity of facet joint sagittalization. (b-d) Facet joint preservation is defined as the postoperative length divided by the preoperative length (ipsilateral facet joint preservation: $\mathrm{A}^{\prime} / \mathrm{A}$; contralateral facet joint preservation: $\left.\mathrm{B}^{\prime} / \mathrm{B}\right)$.

This study was approved by the institutional review board of Izumi Municipal Hospital.

The clinical data investigated were age, body mass index (BMI), number of levels decompressed, length of incision, operative time, intraoperative blood loss, Japanese Orthopaedic Association (JOA) score recovery rate $[9,10]$ between preoperative and final follow up, surgical complications, and total length of postoperative follow-up period. The imaging findings (Table 1) investigated included the crosssectional areas (CSAs) of the subarachnoid space and bilateral multifidus at the middle of the decompressed intervertebral level, preoperative sagittalization of the facet joint, length of the facet joint, change in slippage, alignment of the lumbar spine (L1-L5) and surgical site (e.g., for decompression of L3/L4/L5, the angle of L3-L5 was measured), range of motion (ROM), and rotational angle.

\begin{tabular}{|c|c|c|c|c|c|c|c|c|}
\hline & $\begin{array}{l}\text { CSA: } \\
\text { subarachnoid } \\
\text { space }\end{array}$ & $\begin{array}{l}\text { CSA: } \\
\text { multifidus }\end{array}$ & $\begin{array}{l}\text { Sagittalization of } \\
\text { the facet joint }\end{array}$ & $\begin{array}{l}\text { Length of the } \\
\text { facet joint }\end{array}$ & $\begin{array}{l}\text { Change of } \\
\text { slippage }\end{array}$ & Alignment & ROM & $\begin{array}{l}\text { Rotational } \\
\text { angle }\end{array}$ \\
\hline \multicolumn{9}{|c|}{ Level } \\
\hline $\begin{array}{ll}\text { Each level } & \text { lecompressed }\end{array}$ & * & * & * & * & * & -- & * & * \\
\hline Surgical site & -- & -- & -- & -- & -- & * & -- & -- \\
\hline
\end{tabular}


Citation: Morita M, Nakamura H (2017) Comparison of Three Different Paraspinous Unilateral Approaches to the Spinal Canal for Lumbar

\begin{tabular}{|c|c|c|c|c|c|c|c|c|}
\hline L1-L5 & -- & -- & -- & -- & -- & * & * & * \\
\hline Modality & -- & -- & -- & -- & -- & -- & -- & -- \\
\hline $\begin{array}{l}\text { Upright } \\
\text { anteroposterior view }\end{array}$ & -- & -- & -- & -- & -- & * & -- & -- \\
\hline Upright lateral view & -- & -- & -- & -- & -- & $\begin{array}{l}\text { * (kyphosis +, } \\
\text { lordosis -) }\end{array}$ & -- & -- \\
\hline $\begin{array}{l}\text { Decubitus lateral } \\
\text { flexion-extension } \\
\text { view }\end{array}$ & -- & -- & -- & -- & * & -- & * & -- \\
\hline MRI & * & * & -- & -- & -- & -- & -- & * \\
\hline CT & -- & -- & * & * & -- & -- & -- & -- \\
\hline Calculation & -- & -- & -- & -- & -- & -- & -- & -- \\
\hline $\begin{array}{l}\text { The difference (post- } \\
\text { pre) }\end{array}$ & -- & -- & -- & -- & * & * & * & $*$ \\
\hline The ratio (post/pre) & * & $*$ & -- & $\begin{array}{l}{ }^{*} \text { (facet } \\
\text { preservation) }\end{array}$ & -- & -- & -- & -- \\
\hline
\end{tabular}

Table 1: The imaging findings.

Changes in imaging findings between preoperative and final followup studies (X-ray and MRI), or between preoperative studies and those at 1 week after surgery (CT), were compared. The difference (postoperative subtracted from preoperative measurement) or the ratio (postoperative divided by preoperative measurement) of these imaging findings was used to examine statistical significances among the 3 groups. The correlation between preoperative facet joint sagittalization and preservation (postoperative divided by preoperative length of the facet joint) was also investigated (Figure 2).

These imaging findings were measured by Synapse, ver. 3.2.1 (FUJIFILM Medical, Tokyo, Japan). The Tukey-Kramer multiple comparisons procedure was used to investigate statistical significance among the 3 groups by BellCurve for Excel, ver.2.00 (SSRI, Tokyo, Japan), and a p-value less than 0.05 was considered significant. Pearson's correlation coefficient was used to investigate the relationship between facet joint sagittalization and preservation by Office Excel 2007, ver.12.06755.50000 (Microsoft, Washington, USA).

\section{Results}

\section{Clinical data}

Preoperative JOA scores were higher in group C than in groups A and $\mathrm{B}$. In comparing the results, no significant difference was observed among the 3 groups in age, BMI, or total length of postoperative follow-up period. Due to the retrospective nature of this study, a significant difference was seen between groups $\mathrm{A}$ and $\mathrm{C}$ in the number of levels decompressed. For comparison purposes, parameters for length of incision, operative time, and intraoperative blood loss were divided by the number of levels decompressed. A significant difference in length of incision and intraoperative blood loss per level decompressed was seen with group $\mathrm{A}>\mathrm{B}>\mathrm{C}$. Operative time per level decompressed was longer in group $\mathrm{C}$ than in groups $\mathrm{A}$ or $\mathrm{B}$. JOA score recovery rate was lower in group $B$ than in group $C$ (Tables 2 and 3).

\begin{tabular}{|c|c|c|c|c|c|c|}
\hline \multirow[b]{2}{*}{ Groups } & \multicolumn{6}{|c|}{ Mean value (mean \pm standard deviation) } \\
\hline & A & B & C & A-B & B-C & A-C \\
\hline \multicolumn{7}{|c|}{ Clinical data } \\
\hline JOA score & $12.9 \pm 3.5$ & $13.2 \pm 4.8$ & $16.9 \pm 3.0$ & 0.722 & $0.005^{*}$ & $0.000^{*}$ \\
\hline \multicolumn{7}{|c|}{ Imaging findings } \\
\hline CSA of subarachnoid space $\left(\mathrm{mm}^{2}\right)$ & $60.9 \pm 19.6$ & $62.3 \pm 27.4$ & $61.5 \pm 25.5$ & 0.956 & 0.99 & 0.914 \\
\hline CSA of ipsilateral multifidus & $413 \pm 265$ & $396 \pm 121$ & $382 \pm 99$ & 0.871 & 0.918 & 0.663 \\
\hline CSA of contralateral multifidus & $392 \pm 169$ & $385 \pm 118$ & $387 \pm 87$ & 0.957 & 0.996 & 0.981 \\
\hline
\end{tabular}


Citation: Morita M, Nakamura H (2017) Comparison of Three Different Paraspinous Unilateral Approaches to the Spinal Canal for Lumbar Decompression-Minimally 2-Year Postoperative Evaluation. J Spine 6: 381. doi:10.4172/2165-7939.1000381

Page 4 of 7

\begin{tabular}{|c|c|c|c|c|c|c|}
\hline $\begin{array}{l}\text { Ipsilateral facet joint } \\
\text { (degree) }\end{array}$ sagittalization & $27.1 \pm 11.1$ & $35.2 \pm 11.6$ & $33.8 \pm 12.9$ & $0.001^{*}$ & 0.828 & $0.011^{*}$ \\
\hline Contralateral facet joint sagittalization & $26.1 \pm 10.7$ & $36.1 \pm 11.7$ & $33.3 \pm 11.2$ & $0.000^{*}$ & 0.414 & $0.003^{*}$ \\
\hline Length of ipsilateral facet joint $(\mathrm{mm})$ & $15.2 \pm 3.0$ & $14.1 \pm 2.7$ & $15.3 \pm 2.9$ & 0.23 & 0.238 & 0.995 \\
\hline Length of contralateral facet joint & $15.4 \pm 3.0$ & $14.1 \pm 2.7$ & $15.2 \pm 2.2$ & 0.098 & 0.243 & 0.882 \\
\hline Change of slippage & $0.35 \pm 0.87$ & $0.52 \pm 0.92$ & $0.67 \pm 1.0$ & 0.579 & 0.696 & 0.182 \\
\hline \multicolumn{7}{|c|}{ Alignment (degree) } \\
\hline A-P: L1-L5 & $4.1 \pm 5.0$ & $2.5 \pm 2.9$ & $4.4 \pm 5.6$ & 0.394 & 0.257 & 0.958 \\
\hline A-P: surgical site & $4.6 \pm 4.6$ & $2.9 \pm 3.1$ & $2.9 \pm 2.4$ & 0.138 & 0.997 & 0.16 \\
\hline Lateral: L1-L5 & $-19.8 \pm 10.1$ & $-25.6 \pm 14.9$ & $-27.1 \pm 11.3$ & 0.169 & 0.884 & 0.062 \\
\hline Lateral: surgical site & $-14.7 \pm 8.7$ & $-19.9 \pm 12.2$ & $-18.1 \pm 9.4$ & 0.107 & 0.909 & 0.239 \\
\hline \multicolumn{7}{|c|}{ ROM (degree) } \\
\hline Lateral: L1-L5 & $21.0 \pm 10.1$ & $19.1 \pm 9.8$ & $17.2 \pm 8.8$ & 0.717 & 0.733 & 0.281 \\
\hline Lateral: each level decompressed & $4.8 \pm 3.9$ & $4.4 \pm 3.6$ & $6.6 \pm 4.2$ & 0.875 & $0.014^{*}$ & $0.038^{*}$ \\
\hline \multicolumn{7}{|c|}{ Roatational angle (degree) } \\
\hline L1-L5 & $3.2 \pm 3.3$ & $3.1 \pm 3.6$ & $2.1 \pm 2.5$ & 0.992 & 0.471 & 0.401 \\
\hline Each level decompressed & $2.2 \pm 2.2$ & $2.3 \pm 2.0$ & $2.0 \pm 1.6$ & 0.944 & 0.738 & 0.889 \\
\hline
\end{tabular}

Table 2: Mean value and statistical analysis for preoperative clinical data and imaging findings.

\begin{tabular}{|c|c|c|c|c|c|c|}
\hline \multirow[t]{2}{*}{ Clinical data } & \multicolumn{6}{|c|}{ Mean value (mean \pm standard deviation) } \\
\hline & Group A & Group B & Group C & Groups A-B & Groups B-C & Groups A-C \\
\hline Age (years) & $70 \pm 10$ & $72 \pm 9$ & $71 \pm 8$ & 0.662 & 0.955 & 0.832 \\
\hline BMI (\%) & $24.3 \pm 3.0$ & $22.8 \pm 3.2$ & $23.1 \pm 3.2$ & 0.169 & 0.93 & 0.317 \\
\hline Number of levels decompressed & $2.2 \pm 0.8$ & $1.9 \pm 0.8$ & $1.50 \pm 0.5$ & 0.338 & 0.091 & $0.002^{* *}$ \\
\hline *Length of incision (mm) & $49.8 \pm 13.9$ & $25.3 \pm 10.8$ & $18 \pm 0$ & $0.000^{* *}$ & $0.019^{\star *}$ & $0.000^{* *}$ \\
\hline${ }^{*}$ Operation time (min) & $57.3 \pm 14.9$ & $54.1 \pm 22.3$ & $101.6 \pm 24.3$ & 0.82 & $0.000^{* *}$ & $0.000^{* *}$ \\
\hline *Intraoperative blood loss (g) & $165 \pm 84$ & $99 \pm 87$ & $27 \pm 43$ & $0.002^{* *}$ & $0.001^{* *}$ & $0.000^{* *}$ \\
\hline Recovery rate of JOA score (\%) & $60.0 \pm 26.4$ & $53.0 \pm 29.6$ & $75.8 \pm 24.5$ & 0.578 & $0.004^{\star *}$ & 0.064 \\
\hline $\begin{array}{l}\text { Postoperative follow up period } \\
\text { (Month) }\end{array}$ & $39 \pm 8$ & $42 \pm 9$ & $38 \pm 8$ & 0.21 & 0.124 & 0.96 \\
\hline \multicolumn{7}{|c|}{ Imaging findings } \\
\hline $\begin{array}{l}\text { Change ratio of CSA of } \\
\text { subarachnoid space }\end{array}$ & $2.8 \pm 1.2$ & $2.4 \pm 1.0$ & $2.4 \pm 1.1$ & 0.07 & 0.989 & 0.132 \\
\hline $\begin{array}{l}\text { Change ratio of CSA of } \\
\text { ipsilateral multifidus }\end{array}$ & $0.82 \pm 0.20$ & $0.91 \pm 0.18$ & $0.97 \pm 0.90$ & $0.013^{\text {** }}$ & 0.204 & $0.000^{* *}$ \\
\hline $\begin{array}{l}\text { Change ratio of CSA of } \\
\text { contralateral multifidus }\end{array}$ & $0.89 \pm 0.20$ & $0.98 \pm 0.14$ & $0.99 \pm 0.08$ & $0.005^{* *}$ & 0.959 & $0.004^{* *}$ \\
\hline Ipsilateral facet joint preservation & $0.80 \pm 0.12$ & $0.84 \pm 0.14$ & $0.86 \pm 0.11$ & 0.215 & 0.634 & $0.035^{\star *}$ \\
\hline
\end{tabular}


Citation: Morita M, Nakamura H (2017) Comparison of Three Different Paraspinous Unilateral Approaches to the Spinal Canal for Lumbar Decompression-Minimally 2-Year Postoperative Evaluation. J Spine 6: 381. doi:10.4172/2165-7939.1000381

Page 5 of 7

\begin{tabular}{|c|c|c|c|c|c|c|}
\hline $\begin{array}{l}\text { Contralateral facet joint } \\
\text { preservation }\end{array}$ & $0.77 \pm 0.12$ & $0.94 \pm 0.08$ & $0.92 \pm 0.09$ & $0.000^{* *}$ & 0.458 & $0.000^{\star *}$ \\
\hline Change of slippage $(\mathrm{mm})$ & $0.62 \pm 1.22$ & $0.20 \pm 1.29$ & $0.07 \pm 0.72$ & 0.103 & 0.842 & $0.036^{*}$ \\
\hline \multicolumn{7}{|c|}{ Change of alignment (degree) } \\
\hline A-P: L1-L5 & $-0.07 \pm 3.71$ & $0.77 \pm 2.69$ & $1.50 \pm 2.39$ & 0.528 & 0.609 & 0.11 \\
\hline A-P: surgical site & $1.03 \pm 2.74$ & $0.63 \pm 3.03$ & $0.80 \pm 2.89$ & 0.854 & 0.973 & 0.948 \\
\hline Lateral: L1-L5 & $-0.83 \pm 9.85$ & $-4.23 \pm 7.86$ & $1.03 \pm 6.44$ & 0.246 & $0.049^{* *}$ & 0.72 \\
\hline Lateral: surgical site & $-1.47 \pm 7.94$ & $-2.90 \pm 6.77$ & $0.83 \pm 5.63$ & 0.697 & 0.093 & 0.398 \\
\hline \multicolumn{7}{|c|}{ ROM (degree) } \\
\hline Lateral: L1-L5 & $-0.47 \pm 1.31$ & $-0.80 \pm 8.74$ & $5.03 \pm 7.51$ & 0.991 & 0.07 & 0.093 \\
\hline $\begin{array}{l}\text { Lateral: each level } \\
\text { decompressed }\end{array}$ & $-0.38 \pm 2.86$ & $-1.14 \pm 2.93$ & $0.67 \pm 3.72$ & 0.382 & $0.012^{* *}$ & 0.198 \\
\hline \multicolumn{7}{|c|}{ Rotational angle (degree) } \\
\hline L1-L5 & $-0.17 \pm 2.51$ & $0.40 \pm 3.11$ & $0.17 \pm 2.38$ & 0.693 & 0.94 & 0.881 \\
\hline Each level decompressed & $0.66 \pm 2.55$ & $0.04 \pm 2.67$ & $0.62 \pm 2.45$ & 0.373 & 0.487 & 0.997 \\
\hline \multicolumn{7}{|c|}{ r-value } \\
\hline $\begin{array}{l}\text { Ipsilateral facet joint } \\
\text { sagittalization - preservation }\end{array}$ & ${ }^{* *} r=0.32$ & $r=0.23$ & $r=0.17$ & - & - & - \\
\hline $\begin{array}{l}\text { Contralateral facet joint } \\
\text { sagittalization - preservation }\end{array}$ & ${ }^{* *} r=0.48$ & ${ }^{* *} \mathrm{r}=0.30$ & $r=0.27$ & - & - & - \\
\hline
\end{tabular}

Table 3: Results of mean value and statistical analysis for comparative study.

No complications, including dural tear, infection, hematoma, venous thrombosis, or neurological deficit, were found in the surgical or clinical records.

\section{Imaging findings}

Preoperative ROM at each level decompressed was greater in group C than in groups A or B. Sagittalization of ipsilateral and contralateral facet joints was more severe in group A than in groups B or C. In comparing the results, no significant difference was observed among the 3 groups in the change ratio of the CSA of the subarachnoid space. The change ratios of the CSA of the ipsilateral and contralateral multifidus were smaller in group A than in groups B or C. Ipsilateral facet joint preservation was less in group A than group C, and contralateral facet joint preservation was less in group $\mathrm{A}$ than in groups $\mathrm{B}$ or $\mathrm{C}$. The difference in change in slippage was greater in group A than in group C. No significant difference was observed in change of alignment, except for on the lateral view of the lumbar spine, which showed the difference was less in group B than in group C (group B: kyphotic change; group C: lordotic change). The difference in $\mathrm{ROM}$ at each level decompressed showed significance with Group $\mathrm{B}<\mathrm{C}$. No statistical difference was observed in rotational angle.

Pearson's correlation coefficient between preoperative facet joint sagittalization and preservation was the highest $(\mathrm{r}=0.48)$ in relation to contralateral facet joint sagittalization and preservation in group $\mathrm{A}$ (Tables 2 and 3 ).

\section{Comparison of clinical results and imaging findings overall}

The mean preoperative CSA of the subarachnoid space in all 3 groups was $62.0 \mathrm{~mm}^{2} \pm 25.4 \mathrm{~mm}^{2}$ (average \pm standard deviation), and the mean postoperative value was $142.4 \mathrm{~mm}^{2} \pm 44.3 \mathrm{~mm}^{2}$. The mean CSA value showed a significant improvement after surgery $(\mathrm{P}<0.05)$ [11]. Pearson's correlation coefficient was examined for all 3 groups (Table 4) to compare the following variables: age and preoperative JOA score, age and JOA score recovery rate, age and the number of levels decompressed, age and lowest CSA value among the levels decompressed, number of levels decompressed and preoperative JOA score, number of levels decompressed and JOA score recovery rate, preoperative JOA score and lowest CSA value among the levels decompressed, and preoperative JOA score and recovery rate of JOA score. Although all the correlation coefficients were relatively low, there was mild negative correlation between age and preoperative JOA score $(\mathrm{r}=-0.361)$, and between the number of levels decompressed and preoperative JOA score $(\mathrm{r}=-0.309)$.

\begin{tabular}{|l|l|}
\hline Variables & $\begin{array}{l}\mathbf{r}- \\
\text { value }\end{array}$ \\
\hline Age-Preoperative JOA score & ${ }^{*}-0.361$ \\
\hline
\end{tabular}




\begin{tabular}{|l|l|}
\hline Age-JOA score recovery rate & -0.159 \\
\hline Age-Number of levels decompressed & ${ }^{*} 0.24$ \\
\hline Age-Lowest CSA value among the levels decompressed & -0.168 \\
\hline Number of levels decompressed-Preoperative JOA score & ${ }^{*}-0.309$ \\
\hline Number of levels decompressed-JOA score recovery rate & -0.2 \\
\hline $\begin{array}{l}\text { Preoperative JOA score-Lowest CSA value among the levels } \\
\text { decompressed }\end{array}$ & 0.023 \\
\hline Preoperative JOA score-JOA score recovery rate & ${ }^{*} 0.21$ \\
\hline
\end{tabular}

JOA: Japanese Orthopaedic Association; CSA: Cross Sectional Area; * $p<0.05$

Table 4: The correlation of clinical and imaging data overall 3 groups.

\section{Discussion}

Postoperative problems concerning posterior lumbar surgery mainly consist of paravertebral muscle damage and spinal degeneration, which could induce muscle atrophy, spinal instability, and failed back surgery syndrome. To reduce surgical invasiveness, various less invasive techniques have been developed [1,3,12-14], and comparative studies have shown that less invasive surgeries have benefits compared to conventional surgeries in relation to operative time, estimated blood loss, lumbar muscle destruction, and complications. Among patients with spondylolisthesis who underwent less invasive decompression surgery, Mori et al. [15] revealed that there was a significant increase in the percentage of slip at postoperative year 2 , and some previous studies pointed out risk factors for postoperative slippage [16,17]. There must be causal relationships between surgical invasiveness, preexisting risk factors and postoperative changes, accurate predictions for postoperative slippage, worsening in spinal alignment, and persistent low back pain is still impossible.

The present study was performed under the assumption that invasiveness would be greater in group A (conventional open surgery) than in groups B or C (less invasive surgery) for at least 2 years, and that some comparative results would be expected to show statistical differences that would suggest advantages of less invasive surgery such as length of incision, intraoperative blood loss per level decompressed, multifidus and contralateral facet joint preservation among three groups. Moreover, statistical differences were also showed in ipsilateral facet joint preservation and change of slippage between groups A and C. Considering these statistical differences in this study, less invasive surgery would be superior to conventional open surgery. However, preoperative factors could not be excluded because sagittalization of ipsilateral and contralateral facet joints was more severe in group A than in groups B or C.

On the other hand, some data resulted in complicated statistical differences between groups $\mathrm{B}$ and $\mathrm{C}$ such as JOA score recovery rate, change in lateral alignment in the lumbar spine, and a difference in ROM at each level decompressed.

When micro-endoscopic decompression was introduced at our institution, decompression within 2 levels was indicated given the learning curve of this method. This was thought to be the reason why a statistical difference in the number of levels decompressed was seen between groups A and C. Additionally, patients in group $\mathrm{C}$ were at the beginning of a case series examining micro-endoscopic decompression. This was thought to be the reason why operative time was longer in group C than in groups A or B. In fact, the average operative time per single level of micro-endoscopic decompression in the 30 consecutive cases, which were performed followed by 200 completed cases, was $58.3 \mathrm{~min} \pm 8.0 \mathrm{~min}$. Using this data, there is no statistical difference in operative time per level decompressed among the 3 groups. Once the definite learning curve is over and experience has been acquired, the operative time should be shorter than at the beginning of a case series [18-21].

Even though Pearson's correlation coefficient between preoperative facet joint sagittalization and preservation was relatively low in all groups, all values indicated positive correlation. This may indicate that the more severe the facet joint sagittalization, the more difficult the facet preservation because spine surgeons must angle the chisel or tubular retractor to reset the medial facet according to the severity of facet joint sagittalization. Considering that the positive correlation between preoperative bilateral facet joint sagittalization and preservation was highest in group A, there is another possibility that the more extensive the exposure of the surgical field, the more facet joint preservation would be influenced by the severity of facet joint sagittalization.

\section{Conclusion}

In conclusion, this study revealed that bilateral decompression via a unilateral approach using mini open or micro-endoscopic procedures could be better surgical interventions compared to a conventional unilateral open approach for paravertebral muscle and facet joint preservation for at least 2 years. However, there are limitations of this study. Because this study was performed without a control group with conservative treatments which would indicate the influences of degenerative aging process without decompression surgery, this study could not suggest how low the influences of mini open or microendoscopic procedures upon degenerative changes in lumbar spine.

\section{References}

1. Rahman M, Summers LE, Richter B, Mimran RI, Jacob RP (2008) Comparison of techniques for decompressive lumbar laminectomy: The minimally invasive versus the "Classic" open approach. Minim Invasive Neurosurg 51: 100-105.

2. Stevens KJ, Spenciner DB, Griffiths KL, Kim KD, Zwienenberg-Lee M, et al. (2006) Comparison of minimally invasive and conventional open posterolateral lumbar fusion using magnetic resonance imaging and retraction pressure studies. J Spinal Disord Tech 19: 77-86.

3. Khoo LT, Fessler RG (2002) Microendoscopic decompressive laminotomy for the treatment of lumbar stenosis. Neurosurgery 51: S146-S154.

4. Kim CW (2010) Scientific basis of minimally invasive spine surgery: prevention of multifidus muscle injury during posterior lumbar surgery. Spine 35: S281-S286.

5. Mobbs RJ, Li J, Sivabalan P, Raley D, Rao PJ (2014) Outcomes after decompressive laminectomy for lumbar spinal stenosis: Comparison between minimally invasive unilateral laminectomy for bilateral decompression and open laminectomy: clinical article. J Neurosurg Spine 21: $179-186$.

6. Uehara M, Takahashi J, Hashidate H, Mukaiyama K, Kuraishi S, et al. (2014) Comparison of spinous process-splitting laminectomy versus conventional laminectomy for lumbar spinal stenosis. Asian Spine J 8: 768-776.

7. Nerland US, Jakola AS, Solheim O, Weber C, Rao V, et al. (2015) Minimally invasive decompression versus open laminectomy for central stenosis of the lumbar spine: Pragmatic comparative effectiveness study. BMJ 1: 350 . 
Citation: Morita M, Nakamura H (2017) Comparison of Three Different Paraspinous Unilateral Approaches to the Spinal Canal for Lumbar Decompression-Minimally 2-Year Postoperative Evaluation. J Spine 6: 381. doi:10.4172/2165-7939.1000381

Page 7 of 7

8. Yaman O, Ozdemir N, Dagli AT, Acar E, Dalbayrak S, et al. (2015) A Comparison of bilateral decompression via unilateral approach and classic laminectomy in patients with lumbar spinal stenosis: A retrospective clinical study. Turk Neurosurg 25: 239-245.

9. Japanese Orthopaedic Association (1996) Japanese Orthopaedic Association assessment criteria guidelines manual. JOA. pp. 46-49.

10. Hirabayashi K, Watanabe K, Wakano K, Suzuki N, Satomi K, et al. (1983) Expansive open-door laminoplasty for cervical spinal stenotic myelopathy. Spine 8: 693-696.

11. Prasad BC, Ramesh Chandra VV, Devi BV, Chivukula SS, Pundarikakshaiah K (2016) Clinical, radiological, and functional evaluation of surgical treatment in degenerative lumbar canal stenosis. Neurol India 64: 677-683.

12. Jang JW, Park JH, Hyun SJ, Rhim SC (2012) Clinical outcomes and radiologic changes following microsurgical bilateral decompression via a unilateral approach in patients with lumbar canal stenosis and grade I degenerative spondylolisthesis with a minimum 3-year Follow-up. J Spinal Disord Tech

13. Mannion RJ, Guilfoyle MR, Efendy J, Nowitzke AM, Laing RJ, et al. (2012) Minimally invasive lumbar decompression: long-term outcome, morbidity, and the learning curve from the first 50 cases. J Spinal Disord Tech 25: 47-51.

14. Asamoto S, Muto J, Jimbo H (2016) Minimally invasive space shuttle laminotomy for degenerative lumbar spinal canal stenosis. J Craniovertebr Junction Spine 7: 55-58
15. Mori G, Mikami Y, Arai Y, Ikeda T, Nagae M, et al. (2016) Outcomes in cases of lumbar degenerative spondylolisthesis more than 5 years after treatment with minimally invasive decompression: examination of preand postoperative slippage, intervertebral disc changes, and clinical results. J Neurosurg Spine 24: 367-374.

16. Okuda S, Iwasaki M, Miyauchi A, Aono H, Morita M, et al. (2004) Risk factors for adjacent segment degeneration after PLIF. Spine 29: 1535-1540.

17. Abumi K, Panjabi MM, Kramer KM, Duranceau J, Oxland T, et al. (1990) Biomechanical evaluation of lumbar spinal stability after graded facetectomies. Spine 15: 1142-1147.

18. Jhala A, Mistry M (2010) Endoscopic lumbar discectomy: Experience of first 100 cases. Indian J Orthop 44: 184-190.

19. Lee JC, Jang HD, Shin BJ (2012) Learning curve and clinical outcomes of minimally invasive transforaminal lumbar interbody fusion: Our experience in 86 consecutive cases. Spine 37: 1548-1557.

20. Yadav YR, Parihar V, Kher Y, Bhatele PR (2016) Endoscopic inter laminar management of lumbar disease. Asian J Neurosurg 11: 1-7.

21. Haddadi K, Ganjeh Qazvini HR (2016) Outcome after surgery of lumbar spinal stenosis: A randomized comparison of bilateral laminotomy, trumpet laminectomy, and conventional laminectomy. Front Surg 3: 19. 